\title{
BMJ Open Knowledge, beliefs and attitudes of Muslim footballers towards Ramadan fasting during the London 2012 Olympics: a cross-sectional study
}

\author{
Abdulaziz Farooq, ${ }^{1}$ Christopher P Herrera, ${ }^{2}$ Yacine Zerguini, ${ }^{3}$ Fuad Almudahka, ${ }^{4}$ \\ Karim Chamari ${ }^{1}$
}

To cite: Farooq $A$, Herrera CP, Zerguini Y, et al. Knowledge, beliefs and attitudes of Muslim footballers towards Ramadan fasting during the London 2012 Olympics: a crosssectional study. BMJ Open 2016;6: 012848 . doi:10.1136/bmjopen-2016012848

- Prepublication history and additional material is available. To view please visit the journal (http://dx.doi.org/ 10.1136/bmjopen-2016012848)

Received 27 May 2016 Revised 16 August 2016 Accepted 17 August 2016

CrossMark

For numbered affiliations see end of article.

Correspondence to Abdulaziz Farooq, Mohammed.farooq@aspetar. com

\section{ABSTRACT}

Objectives: Muslims observe fasting during the month of Ramadan by abstaining from eating and drinking from dawn to sunset. Available literature shows that although several studies have been conducted on athletes to determine the effects of Ramadan fasting in terms of physical fitness and performance, little data are available regarding the knowledge, beliefs and attitudes of athletes (particularly footballers) towards Ramadan fasting during high-level competitions. This study explored the knowledge, beliefs and attitudes towards Ramadan fasting among football players participating in the London 2012 Olympics football tournament.

Design: Cross-sectional study.

Settings: Team training facility.

Participants: 54 Muslim footballers participating in the London Olympics, 2012

Outcome measures: Each participant was asked to complete a pre-validated structured questionnaire to assess knowledge, beliefs and attitudes regarding Ramadan fasting and their intention to fast during London 2012.

Results: Of the 54 participating athletes, 21(39\%) reported that they intended to fast during Ramadan, but not on a match day. This attitude differed across three teams interviewed - $83 \%, 15 \%$ and $0 \%$-showing cross-cultural variation. Overall, there was a lack of knowledge among footballers regarding the effects of Ramadan fasting on sleep and performance; around 30\% of athletes gave incorrect responses. This knowledge was independent of their decision to fast on non-competition days $(\mathrm{p}>0.05)$.

Conclusions: This is the first study to describe the knowledge, beliefs and attitudes towards Ramadan fasting among athletes from Muslim-majority countries participating in a high-level competition. Appropriate knowledge can ensure optimum performance for athletes during Ramadan fasting. Coaches, family members and friends also in possession of this knowledge can provide moral support to the players.

\section{INTRODUCTION}

During the month of Ramadan, a healthy adult Muslim will observe fasting intermittently

\section{Strengths and limitations of this study}

- The first study to assesses the knowledge, beliefs and attitudes towards Ramadan fasting among football players

- The participants were professional athletes participating in a high-level international competition (Olympic Games)

- Self-reported decisions to fast, but not the actual practice of Ramadan fasting, at the event were collected.

- Performance-related outcomes were not assessed.

by avoiding the intake of fluid and food from dawn to sunset for 30 days. Unlike the Gregorian calendar, the Islamic calendar is lunar-based. Hence, Ramadan falls on different dates each year in the Gregorian calendar and can coincide with a major sporting competition. Recently, high-level international competitions have taken place during Ramadan, such as the London 2012 Summer Olympics, the FIFA (Fédération Internationale de Football Association) World Cup 2014 and EURO 2016.

The available literature regarding the common factors involved in detrimental effects on physical performance during Ramadan has shown alterations in circadian rhythm, ${ }^{1}$ changes in sleep (in terms of pattern, architecture and duration), ${ }^{2}{ }^{3}$ physiological, metabolic and hormonal changes, ${ }^{4}$ blood glucose-level reduction, ${ }^{5}$ reduced daytime fluid intake (daytime dehydration $)^{6}$ fall in body temperature ${ }^{7}$ alteration in psychomotor functioning ${ }^{8} 9$ (better during the morning and deteriorating as the day progresses), ${ }^{7}{ }^{10}$ more rapid onset of fatigue and increased incidence of non-contact and overuse injury in footballers. ${ }^{11}$ 
There is limited literature on the effects of Ramadan fasting on the endurance abilities of athletes during the fasting state (ie, daylight period). Theoretically, an inability to refuel or rehydrate before and during a 90 min football game could affect physical and mental performance during the game. In a group of endurance athletes, the rate of perceived exertion (RPE) after endurance-running training was similar among fasters and non-fasters alike throughout Ramadan, ${ }^{12}$ whereas 3 days' intermittent fasting reduced repeated-sprint performance in a laboratory setting. ${ }^{13}$ Moreover, another study observed that, during a fasting state, endurancerunning performance over $60 \mathrm{~min}$ is significantly reduced. Maughan et $a l^{14}$ stressed the importance of providing guidelines and recommendations in order to maintain sports performance and to protect the health of athletes. Despite the occurrence of the abovementioned physiological changes during Ramadan, the direct impact on sports performance remains unclear, largely due to the contradictory results in the current published literature. ${ }^{15} 16$

According to the F-MARC 2006 Ramadan Fasting study, biochemical, nutritional, subjective well-being and performance variables are not adversely affected in young football players observing Ramadan in a controlled training-camp environment. ${ }^{15}$ Similar results were found in a study conducted by Karli $e t a l^{16}$, which concluded that if strength-power exercise is performed regularly and daily intake of food, fluid balance and sleeping time are maintained as before Ramadan, fasting will not adversely affect anaerobic power, capacity and lactate metabolism during and after high-intensity exercise in power athletes. In contrast to these findings, a study conducted by Meckel $e t a l^{17}$ found that Ramadan fasting can lead to a significant decrease in aerobic capacity, speed and jumping performance.

It is well established that with a minimal change in sleep pattern and maintenance of training, athletes show little change in anaerobic power or capacity during the month of Ramadan; any increase in tiredness is attributed to inadequate sleep and the phase shift in fluid intake, rather than due to nutritional deficiency. $^{2} 1418$ There is no evidence that Ramadan induces impairment of maximal oxygen intake during a traditional progressive test of short duration $(10 \mathrm{~min})$; however, performance has been shown to deteriorate with longer periods of endurance exercise. ${ }^{19}{ }^{20}$ Despite existing evidence on the effects of Ramadan fasting, Muslim athletes often have their own knowledge and pre-existing beliefs towards the effects of fasting which translate into their attitudes and practices. This is in part due to their long-standing experience of Ramadan fasting, which usually begins in early childhood, ${ }^{21}$ and partly from their specific individual experiences.

When a sports event occurs during Ramadan, some Muslim athletes will forgo fasting on competition days, whereas others may continue to observe fasting on competition and training days. An athlete's decision whether to fast is affected not only by factors such as knowledge, beliefs, and attitudes but also by the influence of his or her social environment and the level of the competition.

Better management of an athlete's performance during Ramadan fasting requires educational intervention. Therefore, this study aimed to take the first step by determining the prevalence of fasting among footballers in a high-level international sporting competition, as well as establishing the athletes' knowledge, beliefs and attitudes towards fasting.

\section{METHODS}

Footballers were recruited to this cross-sectional study by initially approaching team managers of the national teams representing Muslim-majority countries (Egypt, the United Arab Emirates, Senegal and Morocco) that qualified for the football tournament at the 2012 Summer Olympics in London. Three of the four teams agreed to participate and were labelled as teams A, B and $\mathrm{C}$ to maintain confidentiality. The inclusion criterion was any Muslim footballers who were drafted for the national teams that were represented in the football competition at the London 2012 Olympics. All players identified as Muslims $(\mathrm{n}=54)$ completed the survey, giving a response rate of $100 \%$.

\section{Questionnaire}

To assess the knowledge and attitudes of the players, based on their previous experiences, each athlete completed a structured questionnaire before the tournament and 1 week prior to 19 July 2012 (ie, the beginning of Ramadan month).

The questionnaire was designed for the specific purposes of this study and included a priori determined parameters of importance and known attitudes and beliefs. It was originally prepared in the English language. The questionnaire was translated into Arabic by a bilingual author (FA) and into French by two bilingual authors (YZ, KC). The authors of this study evaluated the questionnaire for criteria, content and construct validity. This was done to ensure that the wording used in the questionnaire was suited to the athletes' cultural context and style of communication without altering the meaning of the questions. The questionnaires were then back translated from Arabic and French to English to ensure consistency across translations.

The questionnaire was self-administered, with assistance provided from a trained interviewer when necessary. The questionnaire was presented in three languages: English, Arabic and French. The questionnaire included items that assessed a player's knowledge, attitudes and beliefs concerning fasting, which were assessed on a 5-point Likert scale in which the athletes could answer 'strongly agree', 'agree', 'neutral' (neither agree nor disagree), 'disagree' or 'strongly disagree' (see online supplementary file). Athletes were also asked whether they planned to fast during Ramadan 
(answer options included 'completely', 'only during training/practice', 'only on match days' or 'never').

We defined 'knowledge' as the information and skills acquired by a person through experience or education. Facts and information in a specific field constitute knowledge. We defined 'belief' as an opinion that Muslim footballers held with respect to fasting. We defined 'attitude' as the position that football players held concerning fasting. The questionnaire was not scored, but each item was individually assessed.

\section{Statistical analysis}

All data were coded and analysed using predictive analytics software (IBM SPSS 21.0, IBM Corp., Armonk, New York, USA). Since each item on the questionnaire was coded on a Likert scale, we used the frequencies and percentages to present the descriptive statistics of the athletes' response to each question. Using the $\chi^{2}$ test, we compared the players' intention to fast with other categorical variables (knowledge, attitudes and beliefs) to determine their association. A value of $p<0.05$ was considered statistically significant.

\section{RESULTS}

During the 2012 London Olympic Games, the fasting duration for Ramadan (timespan from dawn to sunset) was $\sim 17$ hours $27 \mathrm{~min}$. The atmospheric temperature ranged from $14^{\circ} \mathrm{C}$ to $21^{\circ} \mathrm{C}$.

Of the 54 athletes who completed the questionnaire, 33 $(61 \%)$ reported that they were not planning to fast at all during the tournament, whereas the remaining 21 athletes (39\%) reported that they intended to fast during Ramadan but not on a match day. These statistics varied between the teams: A $(83 \%)$, B (15\%) and C $(0 \%)$. None of the 54 athletes surveyed planned to fast during match days.

Footballers agreed that Ramadan fasting reduces sleep quality $(53.7 \%)$, sleep time $(61.2 \%)$, power $(77.8 \%)$ and concentration during a game (69.8\%); however, the decision to fast was independent of these factors. A team coach's preference appeared to be a strong deciding factor in whether the athletes chose to fast. Among the 33 athletes who planned not to fast, 28 (85\%) of these athletes stated that their coach did not want them to fast, whereas only 9 (43\%) of the 21 athletes who planned to fast stated that their coach did not want them to fast $(\mathrm{p}=0.002)$. Most $(\mathrm{n}=37,68 \%)$ athletes thought that even with proper hydration during Suhoor (the time when the last meal is taken by Muslims prior to dawn in preparation for daily fast), their performance would be affected as the day progressed.

On the beliefs set of questions about fasting, 44 $(81.5 \%)$ of the participants agreed or strongly agreed that Ramadan fasting reduces endurance/stamina and $26(48.2 \%)$ agreed or strongly agreed that it reduces mental skills. A high proportion $(n=46,85.2 \%)$ of participants disagreed or strongly disagreed that fasting can increase their physical skills.
On the attitudes set of questions, $42(78 \%)$ of the participants considered fasting for $\sim 17$ hours each day as a 'burden'; $3(5.6 \%)$ of the participants thought that Ramadan fasting would make them physically stronger and $6(11.2 \%)$ thought that it would make them mentally stronger. Thirty-nine $(72.2 \%)$ of the athletes agreed that it was acceptable to skip fasting days during games. Most players (72.2\%) stated a preference for future high-level competitions to not take place during Ramadan. Approximately $40 \%$ of the surveyed athletes reported that there was pressure from family and friends to practise Ramadan fasting on all days of the competition.

\section{DISCUSSION}

For 30 days during the month of Ramadan, Muslims fast from dawn to sunset. This fasting schedule may be particularly challenging, especially for elite-level athletes who participate in international competitions scheduled during Ramadan. To the authors' knowledge, this is the first study to report the prevalence of intentions to practise Ramadan intermittent fasting during an international high-level competition.

Our study found that none of the 54 athletes intended to fast on match days. However, 39\% reported that they would fast for non-competition days (training and rest days). Moreover, there was a substantial variation in how the three teams responded to this question $(0 \%, 15 \%$ and $83 \%$ ), thus suggesting cross-cultural differences in the importance assigned to Ramadan fasting or in how its impact is understood.

According to the available scientific literature, sleep architecture is affected during Ramadan fasting in healthy adult non-athletes and sleep duration during fasting is decreased in healthy adults, ${ }^{22}$ as well as in professional athletes. ${ }^{2}$ In the current study, approximately one-third of the players lacked the knowledge that sleep quality and sleep times are affected during Ramadan (see table 1). Despite the knowledge of effects of Ramadan fasting on sleep duration and quality, the majority of the participants reported that they would fast on non-competition days (see table 2). This could indicate that players are not aware that fasting can influence sleep patterns during the subsequent days.

Some studies have reported a decline in sustained attention or rapid responses among athletes during the daytime, although sustained attention gradually declines from morning to late afternoon. ${ }^{7}{ }^{10}$ Many studies have tested the effects of Ramadan intermittent fasting on cognitive function in athletes under resting conditions; ${ }^{7} 1023$ however, this is clearly not specific to cognitive function during physical effort. In relation to cognitive function, the present study showed that $69.8 \%$ of the footballers thought that their concentration was reduced during a game while fasting. This view was found to be similar in both groups of non-fasters and fasters on non-competitive days $(63.6 \%$ vs $76.2 \%$, 
Table 1 Knowledge, beliefs and attitudes among athletes about Ramadan fasting $(n=54)$

\begin{tabular}{|c|c|c|c|c|c|}
\hline Item & $\begin{array}{l}\text { Strongly } \\
\text { disagree }\end{array}$ & Disagree & Neutral & Agree & $\begin{array}{l}\text { Strongly } \\
\text { agree }\end{array}$ \\
\hline \multicolumn{6}{|l|}{ Beliefs } \\
\hline Ramadan fasting can reduce my endurance/stamina during a game & 3.7 & 5.6 & 9.3 & 46.3 & 35.2 \\
\hline Ramadan fasting will increase my physical skills & 20.4 & 64.8 & 1.9 & 9.3 & 3.7 \\
\hline Ramadan fasting will reduce my mental skills & 9.3 & 22.2 & 20.4 & 38.9 & 9.3 \\
\hline Ramadan fasting will increase my confidence & 3.7 & 20.4 & 22.2 & 37.0 & 16.7 \\
\hline \multicolumn{6}{|l|}{ Knowledge } \\
\hline Ramadan fasting will reduce my sleep quality & 16.7 & 22.2 & 7.4 & 40.7 & 13.0 \\
\hline $\begin{array}{l}\text { If I am properly hydrated at Suhoor, I can participate in a game or } \\
\text { training without any problem while fasting }\end{array}$ & 11.1 & 57.4 & 20.4 & 5.6 & 5.6 \\
\hline Ramadan fasting will reduce my concentration during game & 7.5 & 15.1 & 7.5 & 52.8 & 17.0 \\
\hline Ramadan fasting will reduce my sleep time & 13.0 & 22.2 & 3.7 & 51.9 & 9.3 \\
\hline Ramadan fasting can reduce my power during a game & 3.7 & 5.6 & 13.0 & 59.3 & 18.5 \\
\hline \multicolumn{6}{|l|}{ Attitudes } \\
\hline 17 hours of Ramadan fasting in the UK can be a challenge & 0 & 5.6 & 16.7 & 46.3 & 31.5 \\
\hline Ramadan fasting will make me physically stronger & 13.0 & 72.2 & 9.3 & 3.7 & 1.9 \\
\hline Ramadan fasting will make me mentally stronger & 7.4 & 57.4 & 24.1 & 5.6 & 5.6 \\
\hline I think it is OK to postpone my Ramadan fasting until after the Olympics & 3.7 & 11.1 & 13.0 & 35.2 & 37.0 \\
\hline My family and friends want me to fast in Ramadan & 9.3 & 9.3 & 33.3 & 25.9 & 22.2 \\
\hline It is not a problem for future sports events to take place during Ramadan & 29.6 & 42.6 & 14.8 & 9.3 & 3.7 \\
\hline My coach wants me not to fast in Ramadan & 7.4 & 24.1 & 14.8 & 22.2 & 31.5 \\
\hline Ramadan fasting can make me weaker day by day & 7.4 & 16.7 & 24.1 & 35.2 & 16.7 \\
\hline
\end{tabular}

Table 2 Association between knowledge, beliefs and attitudes of Ramadan fasting among athletes who did and did not decide to fast during the London 2012 Olympic Football Tournament

\begin{tabular}{|c|c|c|c|}
\hline & $\begin{array}{l}\text { Fast on } \\
\text { non-competitive } \\
\text { days }(n=21)\end{array}$ & $\begin{array}{l}\text { Not to fast } \\
(n=33)\end{array}$ & p Value \\
\hline \multicolumn{4}{|l|}{ Beliefs } \\
\hline Ramadan fasting can reduce my endurance/stamina during a game & $17(81.0)$ & $27(81.8)$ & 0.936 \\
\hline Ramadan fasting will reduce my physical skills & 19(90.5) & $27(81.8)$ & 0.383 \\
\hline Ramadan fasting will reduce my mental skills & $10(47.6)$ & $16(48.5)$ & 0.951 \\
\hline Ramadan fasting will increase my confidence & 12(57.1) & $17(51.5)$ & 0.686 \\
\hline \multicolumn{4}{|l|}{ Knowledge } \\
\hline Ramadan fasting will reduce my sleep quality & 17(81.0) & $12(36.4)$ & $0.001^{\star *}$ \\
\hline $\begin{array}{l}\text { If I am properly hydrated at Suhoor, I can participate in a game or training } \\
\text { without any problem while fasting? }\end{array}$ & $0(0.0)$ & 6(18.2) & 0.071 \\
\hline Ramadan fasting will reduce my concentration during game & 16(76.2) & 21(63.6) & 0.383 \\
\hline Ramadan fasting will reduce my sleep time & 18(85.7) & 15(45.5) & $0.003^{\star \star}$ \\
\hline Ramadan fasting can reduce my power during a game & 15(71.4) & $27(81.8)$ & 0.371 \\
\hline \multicolumn{4}{|l|}{ Attitudes } \\
\hline 17 hours of Ramadan fasting in the UK can be a challenge & 18(85.7) & 24(72.7) & 0.263 \\
\hline Ramadan fasting will make me physically stronger & $1(4.8)$ & $2(6.1)$ & 0.839 \\
\hline Ramadan fasting will make me mentally stronger & $0(0.0)$ & $6(18.2)$ & 0.071 \\
\hline I think it is OK to postpone my Ramadan fasting until after the Olympics & $13(61.9)$ & $26(78.8)$ & 0.177 \\
\hline My family and friends want me to fast in Ramadan & $17(81.0)$ & $9(27.3)$ & $<0.001^{\star \star *}$ \\
\hline It is not a problem for future sports events to take place during Ramadan & 2(9.5) & $5(15.2)$ & 0.583 \\
\hline Ramadan fasting can make me weaker day by day & $5(23.8)$ & 23(69.7) & $0.001^{\star \star}$ \\
\hline My coach wants me not to fast in Ramadan & $7(33.3)$ & $22(66.7)$ & $0.017^{\star}$ \\
\hline
\end{tabular}

$\mathrm{p}=0.383$; table 2). Despite the lack of evidence relating to cognitive function while playing a football game in a fasting condition, this finding shows that most of the assessed elite football players in this study believed that
Ramadan intermittent fasting could have a negative impact on their 'mental' abilities during games. However, this view was not associated with their decision to fast on non-competitive days (table 2). 
The importance of being well-hydrated before, during and after strenuous exercise is well established. In particular, hydrating during exercise will influence thermoregulatory and muscle function as well as maintain hydration status to maximise performance. ${ }^{24}$ Only a few hours of fluid deprivation can adversely affect cognitive tasks that rely on speed and accuracy. ${ }^{25}$ Of the footballers assessed in the present study, $68.5 \%$ agreed or strongly agreed that it would not be possible to engage in games or training in a fasting state, despite drinking sufficient water at Suhoor. This shows that they are aware of the importance of hydration while playing. This may be the critical reason as to why none of the players intend to fast on competitive days.

We found that few participants in our study were under the belief that Ramadan fasting can improve endurance $(9.3 \%)$, physical skills $(13.0 \%)$ or mental skills $(31.5 \%)$. Some players also believed that Ramadan fasting makes them physically and mentally stronger (see table 1). Others were neutral about many attitude and belief questions. This neutrality may be as a result of a lack of knowledge on the topic area and/or because they do not want to take a position, especially if this meant going against their religious beliefs. We observed no differences in these attitude and belief items between the two groups.

A study of Tunisian footballers during Ramadan reported that RPE among fasters and non-fasters at training sessions was comparable, despite experiencing similar training loads. ${ }^{26}$ In another study of young soccer players, aerobic and anaerobic physical performances during Ramadan, particularly during the last week of fasting, was significantly diminished. ${ }^{27}$ In our study, among players who reported intending to fast on non-competitive days, $23.8 \%$ believed that Ramadan intermittent fasting could make them weaker day by day, as opposed to $69.7 \%$ among those who reported that they did not intend to fast ( $\mathrm{p}=0.001$; table 2$)$.

Footballers who choose not to fast might face disapproval and criticism from family and friends. In this study, $\sim 40 \%$ of the footballers said that their family and friends insisted that they must observe Ramadan fasting on each Ramadan day. In the context of the players' environment, the team coach's opinion seemed to be of paramount importance. Indeed, the decision whether or not to involve a player in a game is in his hands. It was clearly observed in this study that among the players who intended to fast on non-competitive days, pressure from family and friends and pressure from the team coach were significant factors $(p<0.001$ and $p=0.017$; table 2).

Many footballers stated a preference for important international competitions not to be held during Ramadan, and $72.2 \%$ agreed that it is acceptable to make up the fast on another day. This highlights the possibility that some athletes take their fasting decision against their own will, which could decrease their confidence and morale during the game. As previously mentioned, a player's decision to fast during a competition is not solely based on his past experiences or beliefs, but also on current challenges. The responses regarding the practice of Ramadan fasting in this study were likely to be influenced by the footballers' awareness that they would experience Ramadan in London, where the duration of daylight was 17-18 hours and games were to take place just before sunset in temperate weather conditions. The FIFA World Cup 2014 also coincided with the Ramadan month, but this was during knockout stages when only one Muslim majority country team had qualified. During this competition, matches occurred during daylight hours of shorter duration (1213 hours), but under conditions of high temperature and humidity.

During the London 2012 tournament, the four teams which represented Muslim-majority countries played 14 matches altogether. Only two matches led to victory $(14.2 \%)$ and six matches ended as a draw $(42.8 \%)$.

The main limitation of this study is that the exact prevalence of those practising fasting during Ramadan on training or competitions days could not be determined. For practical reasons, it was not possible to access these athletes during the high-level competition. Although our study had a relatively small sample size of 54 athletes, we were able to recruit three of the four participating teams representing Muslim countries in this high-level competition. The practice of Ramadan fasting may vary among other footballers in different settings and events. The results of the current study regarding the prevalence of Ramadan fasting cannot be generalised to all Muslim athlete populations from different countries, as our results suggests a cultural influence. To assess this more fully, larger prospective studies are required.

There is an increase in scientific research and recommendations into the effects of Ramadan intermittent fasting on hydration, nutrition, performance, sleep and general health. ${ }^{25611}{ }^{28}$ Athletes as well as team coaches and sport organisation bodies need to be aware of the recent updated knowledge, such that proper educational interventions and sports events can be organised to ensure that the health of athletes is protected. The positive or negative attitudes and beliefs about the effects of Ramadan fasting could play a psychological role as a placebo or nocebo effect, ${ }^{29}$ and thus potentially affect the performance. This requires further exploration in future studies to assess the performance of athletes during Ramadan.

\section{CONCLUSION}

The present study found that most participants believed that Ramadan fasting would negatively affect their football match performance. There were cross-cultural differences in how Muslim football players planned to observe Ramadan fasting. Overall, there was a lack of knowledge about the effects of Ramadan fasting in 
approximately one-third of the surveyed elite footballers, which stresses the importance of education sessions to help players to better manage Ramadan intermittent fasting and sports participation. Furthermore, some players, despite having good knowledge about the influence of Ramadan fasting on sleep, and potentially on football performance, still intended to observe fasting due to their religious commitment.

Some potential recommendations to reduce the negative effect of Ramadan on athletic performance for players, coaches and authorities include adjustment of event timing (scheduling events during early morning or late at night; although this is unlikely to be followed in well-known tournaments, where the majority of the participants are non-Muslims), adjustment in sleep pattern (retiring as early as possible after the evening meal and taking a nap after breakfast or whenever possible during the day), prevention of hypoglycaemia (by fat metabolism through endurance training, with consumption of a high-fat diet), maintenance of hydration (through a high carbohydrate diet to maximise pre-game glycogen reserve, intake of salt and water before dawn, avoidance of sweating and activity pre-event), following an appropriate pattern of nutrition (such as increasing the intake of high-quality protein following resistance exercise, to develop a positive nitrogen balance to prevent a decline in peak performance ${ }^{19-22}$ ). When high-level competitions occur during Ramadan, although teams may be able to adhere to some of the above recommendations during training, it will not be possible to modify the settings/schedule on a competition day. Therefore, training programmes should be designed to match the competition needs in parallel with a Ramadan fasting plan. A particularly pertinent point to emerge from this study is the importance of the education of players, coaches and family members about the physiological and psychological effects of Ramadan fasting and the provision of appropriate evidence-based recommendations to ensure optimal performance while still upholding religious and cultural beliefs.

\author{
Author affiliations \\ ${ }^{1}$ Athlete Health and Performance Research, Aspetar, Orthopaedic and Sports \\ Medicine Hospital, Doha, Qatar \\ 2Department of Health and Human Performance, Sul Ross State University, \\ Alpine, Texas, USA \\ ${ }^{3}$ Département Médecine et Traumatologie du Sport, Clinique Chahrazed, \\ Cheraga, Algeria \\ ${ }^{4}$ Exercise is Medicine Department, Aspetar, Orthopaedic and Sports Medicine \\ Hospital, Doha, Qatar
}

Twitter Follow Yacine Zerguini at @YZerguini

Contributors AF and FM designed and developed the questionnaire. All the authors validated the questionnaire and were involved in the study design. KC and $\mathrm{CH}$ supervised the data collection. AF analysed and interpreted the data, and wrote the manuscript. All authors have contributed to and edited the manuscript and have approved the final manuscript.

Funding This research received no specific grant from any funding agency in the public, commercial or not-for-profit sectors.
Competing interests None declared.

Ethics approval The study received ethical approval by the Ethics Council, the institutional review board of Algiers, Algeria.

Provenance and peer review Not commissioned; externally peer reviewed.

Data sharing statement No additional data are available.

Open Access This is an Open Access article distributed in accordance with the Creative Commons Attribution Non Commercial (CC BY-NC 4.0) license, which permits others to distribute, remix, adapt, build upon this work noncommercially, and license their derivative works on different terms, provided the original work is properly cited and the use is non-commercial. See: http:// creativecommons.org/licenses/by-nc/4.0/

\section{REFERENCES}

1. Iraki L, Bogdan A, Hakkou F, et al. Ramadan diet restrictions modify the circadian time structure in humans. A study on plasma gastrin, insulin, glucose, and calcium and on gastric $\mathrm{pH}$. J Clin Endocrinol Metab 1997;82:1261-73.

2. Roky R, Herrera CP, Ahmed Q. Sleep in athletes and the effects of Ramadan. J Sports Sci 2012;30(Suppl 1):S75-84.

3. BaHammam A, Alrajeh M, Albabtain M, et al. Circadian pattern of sleep, energy expenditure, and body temperature of young healthy men during the intermittent fasting of Ramadan. Appetite 2010;54:426-9.

4. Chaouachi A, Coutts AJ, Wong del P, et al. Haematological, inflammatory, and immunological responses in elite judo athletes maintaining high training loads during Ramadan. Appl Physiol Nutr Metab 2009;34:907-15.

5. Burke LM, King C. Ramadan fasting and the goals of sports nutrition around exercise. J Sports Sci 2012;30(Suppl 1):S21-31.

6. Maughan RJ, Shirreffs SM. Hydration and performance during Ramadan. J Sports Sci 2012;30(Suppl 1):S33-41.

7. Roky R, Iraki L, HajKhlifa R, et al. Daytime alertness, mood, psychomotor performances, and oral temperature during Ramadan intermittent fasting. Ann Nutr Metab 2000;44:101-7.

8. Chamari K, Briki W, Faroog A, et al. Impact of Ramadan intermittent fasting on cognitive function in trained cyclists: a pilot study. Biol Sport 2016;33:49-56.

9. Cherif A, Roelands B, Meeusen R, et al. Effects of intermittent fasting, caloric restriction, and Ramadan intermittent fasting on cognitive performance at rest and during exercise in adults. Sports Med 2016;46:35-47.

10. Tian $\mathrm{HH}$, Aziz AR, Png W, et al. Effects of fasting during Ramadan month on cognitive function in Muslim athletes. Asian J Sports Med 2011;2:145-53.

11. Chamari $\mathrm{K}$, Haddad M, Wong DP, et al. Injury rates in professional soccer players during Ramadan. J Sports Sci 2012;30(Suppl 1): S93--102.

12. Havenetidis K. Exercise performance and recovery of Muslim endurance athletes during Ramadan fasting. Int J Sports Sci Coach 2015;10:51-68.

13. Cherif $A$, Meeusen $R$, Faroog $A$, et al. Three days of intermittent fasting: repeated-sprint performance decreased by vertical stiffness impairment. Int J Sports Physiol Perform 2016.

14. Maughan RJ, Zerguini $\mathrm{Y}$, Chalabi $\mathrm{H}$, et al. Ramadan and football. J Sports Sci 2012;30(Suppl 1):S1.

15. Zerguini Y, Dvorak J, Maughan RJ, et al. Influence of Ramadan fasting on physiological and performance variables in football players: summary of the F-MARC 2006 Ramadan fasting study. J Sports Sci 2008;26(Suppl 3):S3-6.

16. Karli U, Guvenc A, Aslan A, et al. Influence of Ramadan fasting on anaerobic performance and recovery following short time high intensity exercise. J Sports Sci Med 2007;6:490-7.

17. Meckel Y, Ismaeel A, Eliakim A. The effect of the Ramadan fast on physical performance and dietary habits in adolescent soccer players. Eur J Appl Physiol 2008;102:651-7.

18. Havenetidis K. Ramadan fasting and endurance running performance in army officer cadets. Int Rev Armed Forces Med Serv 2011;84:68-72.

19. Aziz AR, Wahid MF, Png W, et al. Effects of Ramadan fasting on 60 min of endurance running performance in moderately trained men. Br J Sports Med 2010;44:516-21.

20. Brisswalter J, Bouhlel E, Falola JM, et al. Effects of Ramadan intermittent fasting on middle-distance running performance in well-trained runners. Clin J Sport Med 2011;21:422-7.

21. Farooq A, Herrera CP, Almudahka F, et al. A prospective study of the physiological and neurobehavioral effects of Ramadan fasting in preteen and teenage boys. J Acad Nutr Diet 2015;115:889-97. 
22. Bahammam AS, Alaseem AM, Alzakri AA, et al. The effects of Ramadan fasting on sleep patterns and daytime sleepiness: an objective assessment. J Res Med Sci 2013;18:127-31.

23. Lotfi S, Madani M, Tazi A, et al. [Variation of cognitive functions and glycemia during physical exercise in Ramadan fasting]. Rev Neurol (Paris) 2010;166:721-6.

24. Maughan RJ, Fallah J, Coyle EF. The effects of fasting on metabolism and performance. Br J Sports Med 2010;44:490-4.

25. Petri NM, Dropulic N, Kardum G. Effects of voluntary fluid intake deprivation on mental and psychomotor performance. Croat Med $J$ 2006;47:855-61.
26. Leiper JB, Watson P, Evans G, et al. Intensity of a training session during Ramadan in fasting and non-fasting Tunisian youth football players. J Sports Sci 2008;26(Suppl 3):S71-79.

27. Chtourou $\mathrm{H}$, Hammouda $\mathrm{O}$, Souissi $\mathrm{H}$, et al. The effect of Ramadan fasting on physical performances, mood state and perceived exertion in young footballers. Asian J Sports Med 2011;2:177-85.

28. Kirkendall DT, Chaouachi A, Aziz AR, et al. Strategies for maintaining fitness and performance during Ramadan. J Sports Sci 2012;30(Suppl 1):S103-8.

29. Colloca L, Miller FG. The nocebo effect and its relevance for clinical practice. Psychosom Med 2011;73:598-603. 